\title{
Gene expression profiling of whole blood cells supports a more efficient mitochondrial respiration in hypoxia- challenged gilthead sea bream (Sparus aurata)
}

\author{
Juan Antonio Martos-Sitcha', Azucena Bermejo-Nogales ${ }^{1,2}$, Josep Alvar Calduch-Giner ${ }^{1}$ and Jaume Pérez-Sánchez ${ }^{1 *}$ (D)
}

\begin{abstract}
Background: Acclimation to abiotic challenges, including decreases in $\mathrm{O}_{2}$ availability, requires physiological and anatomical phenotyping to accommodate the organism to the environmental conditions. The retention of a nucleus and functional mitochondria in mature fish red blood cells makes blood a promising tissue to analyse the transcriptome and metabolic responses of hypoxia-challenged fish in an integrative and non-invasive manner.

Methods: Juvenile gilthead sea bream (Sparus aurata) were reared at $20-21{ }^{\circ} \mathrm{C}$ under normoxic conditions $\left(>85 \% \mathrm{O}_{2}\right.$ saturation) followed by exposure to a gradual decrease in water $\mathrm{O}_{2}$ concentration to $3.0 \mathrm{ppm}\left(41-42 \% \mathrm{O}_{2}\right.$ saturation) for $24 \mathrm{~h}$ or $1.3 \mathrm{ppm}\left(18-19 \% \mathrm{O}_{2}\right.$ saturation) for up to $4 \mathrm{~h}$. Blood samples were collected at three different sampling points for haematological, biochemical and transcriptomic analysis.

Results: Blood physiological hallmarks remained almost unaltered at 3.0 ppm, but the haematocrit and circulating levels of haemoglobin, glucose and lactate were consistently increased when fish were maintained below the limiting oxygen saturation at $1.3 \mathrm{ppm}$. These findings were concurrent with an increase in total plasma antioxidant activity and plasma cortisol levels, whereas the opposite trend was observed for growth-promoting factors, such as insulin-like growth factor I. Additionally, gene expression profiling of whole blood cells revealed changes in upstream master regulators of mitochondria ( $p g c \beta$ and $n r f 1)$, antioxidant enzymes ( $g p \times 1, g s t 3$, and sod2), outer and inner membrane translocases (tom70, tom22, tim44, tim 10, and tim9), components of the mitochondrial dynamics system ( $m$ fn2, miffb, miro 1a, and miro2), apoptotic factors (aifm 1), uncoupling proteins (ucp2) and oxidative enzymes of fatty acid $\beta$-oxidation (acca2, ech, and hadh), the tricarboxylic acid cycle (cs) and the oxidative phosphorylation pathway. The overall response is an extensive reduction in gene expression of almost all respiratory chain enzyme subunits of the five complexes, although mitochondrial-encoded catalytic subunits and nuclear-encoded regulatory subunits of Complex IV were primarily increased in hypoxic fish.

Conclusions: Our results demonstrate the re-adjustment of mitochondrial machinery at transcriptional level to cope with a decreased basal metabolic rate, consistent with a low risk of oxidative stress, diminished aerobic ATP production and higher $\mathrm{O}_{2}$-carrying capacity. Taken together, these results suggest that whole blood cells can be used as a highly informative target tissue of metabolic condition.
\end{abstract}

Keywords: Blood transcriptomics, Hypoxia, Limiting oxygen saturation, Mitochondrial activity, Oxphos, Sparus aurata

\footnotetext{
* Correspondence: jaime.perez.sanchez@csic.es

${ }^{1}$ Nutrigenomics and Fish Growth Endocrinology Group, Institute of

Aquaculture Torre de la Sal, Consejo Superior de Investigaciones Científicas

(IATS-CSIC), Ribera de Cabanes, E-12595 Castellón, Spain

Full list of author information is available at the end of the article
} 


\section{Background}

Among the abiotic factors, dissolved oxygen $\left(\mathrm{O}_{2}\right)$ is particularly important as the major limiting factor of fish aerobic metabolism $[1,2]$. When regulatory mechanisms are no longer sufficient to maintain the $\mathrm{O}_{2}$ consumption rate $\left(\mathrm{MO}_{2}\right)$, further reductions in $\mathrm{MO}_{2}$ occur at a certain level of $\mathrm{O}_{2}$ saturation [3]. This threshold is termed the limiting oxygen saturation (LOS) in fed fish able to maintain a routine metabolic rate, and according to the oxystatic control theory of feed intake, fish adjust their feed intake to meet dietary $\mathrm{O}_{2}$ demands [4]. Therefore, changes in LOS, produced by fluctuations in $\mathrm{O}_{2}$ solubility associated with variations in water temperature, should be considered and regulated to ensure a noncompromised physiological function and guarantee the welfare of farmed fish fed high or low $\mathrm{O}_{2}$-demanding diets $[5,6]$. This regulation is mediated through $\mathrm{O}_{2}$ sensors that trigger anaerobic metabolic rates to compensate for the decreasing aerobic ATP production [7, 8]. For this purpose, eukaryotic cells switch from mitochondrial oxidative phosphorylation (OXPHOS) to the less efficient anaerobic glycolytic pathway, which induces stress and lactic acidosis (reviewed in [9]). The hallmarks of human muscle adaptation to hypoxia are a decrease in muscle oxidative capacity concomitant with a decrease in aerobic work capacity [10, 11]. In this regard, hypo-metabolic states should be considered as part of the adaptive response to hypoxia instead of a negative result in hypoxia-tolerant individuals [12] since this metabolic depression prevents the accumulation of toxic by-products from anaerobic metabolism [13].

In fish, microarray gene expression profiling of liver and skeletal muscle demonstrated that metabolic suppression is a key adaptive strategy in the hypoxic goby fish, Gillichthys mirabilis, to drive energy resources from growth towards metabolic processes that are essential for hypoxia survival [14]. However, in Fundulus grandis, both cardiac and hepatic tissues displayed increases in the gene expression of different enzyme subunits of the OXPHOS pathway in response to short-term hypoxic exposure [15]. Similarly, confounding results have been reported in European sea bass (Dicentrarchus labrax), as early life exposure to moderate hypoxia has long-lasting detrimental effects on growth performance with no improvement of hypoxia tolerance in juvenile fish despite the enhanced expression of glycolytic enzymes, which are target genes of hypoxia-inducible factors [16]. Whether this response is tissue- or fish species-specific remains unclear. Importantly, the red blood cells (RBC) of fish and almost all amphibians, reptiles and birds retain a nucleus and functional mitochondria [17]. These RBCs present new research opportunities, and previous research attempts have demonstrated that the expression of mitochondrial uncoupling proteins is highly regulated by hypoxia stimuli in the whole blood cells of gilthead sea bream (Sparus aurata) [8]. Certainly, fish microarray meta-analysis revealed that mitochondria are particularly sensitive to cellular stress triggered by a wide range of nutritional and environmental stress stimuli [18]. Hence, a PCR-array containing 88 mitochondrial-related markers has been useful to examine changes in hepatic and muscle metabolism in response to short-term fasting [19] or aquaculture stressors that mimic thermal stress and daily operational farming activities in gilthead sea bream [20]. There is little information on blood transcriptomics, and the aim of the present study was to provide new insights into the regulation and adaptive responses of hypoxic metabolism in fish, combining non-invasive transcriptional approaches based on mitochondrial markers with conventional measures of blood haematology and biochemistry. This type of approach is crucial to determine whether samples collected without sacrificing animals provide a reliable measure of mitochondrial functioning and energy metabolism at the level of the whole organism.

\section{Methods}

\section{Animal care}

Juvenile gilthead sea bream of Atlantic origin (Ferme Marine du Douhet, Bordeaux, France) were reared from early life stages at the indoor experimental facilities of the Institute of Aquaculture Torre de la Sal (IATS-CSIC, Castellón, Spain) under natural photoperiod and temperature conditions at our latitude $\left(40^{\circ} 5^{\prime} \mathrm{N} ; 0^{\circ} 10^{\prime} \mathrm{E}\right)$. Seawater was pumped ashore (open system) and filtered through a 10$\mu \mathrm{m}$ filter. The $\mathrm{O}_{2}$ content of water effluents under standard conditions remained consistently higher than $85 \%$ saturation, and unionised ammonia under both control and experimental conditions remained below toxic levels $(<0.02 \mathrm{mg} / \mathrm{L})$. For sampling, the fish were anaesthetised using 3-aminobenzoic acid ethyl ester $(100 \mathrm{mg} / \mathrm{L})$, and blood was drawn from caudal vessels using EDTA-treated syringes.

\section{Experimental setup and sampling}

Juvenile fish of $230-260 \mathrm{~g}$ body weight were distributed in 500-L tanks (16 fish per tank) allocated in a recirculatory system equipped with physical and biological filters and programmable temperature. The water temperature was maintained at $20-21{ }^{\circ} \mathrm{C}$. Fish were fed daily to visual satiety using a commercial diet (INICIO Forte 824/EFICO Forte 824; BioMar, Palencia, Spain), and all fish were fasted during the hypoxia challenges. The water conditions for the control fish (normoxic fish) remained unchanged, whereas hypoxic fish experienced a gradual decrease in the water $\mathrm{O}_{2}$ concentration until reaching i) $3.0 \mathrm{ppm}$ (41-42\% $\mathrm{O}_{2}$ saturation; moderate hypoxia, $\mathrm{H} 1)$ for $24 \mathrm{~h}$ or ii) $1.3 \mathrm{ppm}\left(18-19 \% \mathrm{O}_{2}\right.$ saturation; severe hypoxia, $\mathrm{H} 2$ ) for up to $4 \mathrm{~h}$ in two different 
hypoxic tests (Fig. 1). Both low dissolved $\mathrm{O}_{2}$ levels tested were obtained by the cessation of normal aeration in the tank, achieving an accurate balance between the consumption rates of the animals and the supply of clean and oxygenated water by means of an electrovalve within the established $\mathrm{O}_{2}$ steady-state condition.

In each test, normoxic or hypoxia-challenged fish were sampled at three different sampling points after decreasing the water $\mathrm{O}_{2}$ concentration (8 fish per time and condition): i) H1: T0, T1 (24 h), T2 (48 h), and ii) H2: T0, T1 $(7 \mathrm{~h}), \mathrm{T} 2(11 \mathrm{~h})$. One blood aliquot $(150 \mu \mathrm{L})$ was directly collected into a microtube containing $500 \mu \mathrm{L}$ of stabilising lysis solution (REAL Total RNA Spin Blood Kit, Durviz, Valencia, Spain) and stored at $-80{ }^{\circ} \mathrm{C}$ until total RNA extraction. Other aliquots were processed for haematocrit $(\mathrm{Hc})$ and haemoglobin $(\mathrm{Hb})$ determinations.

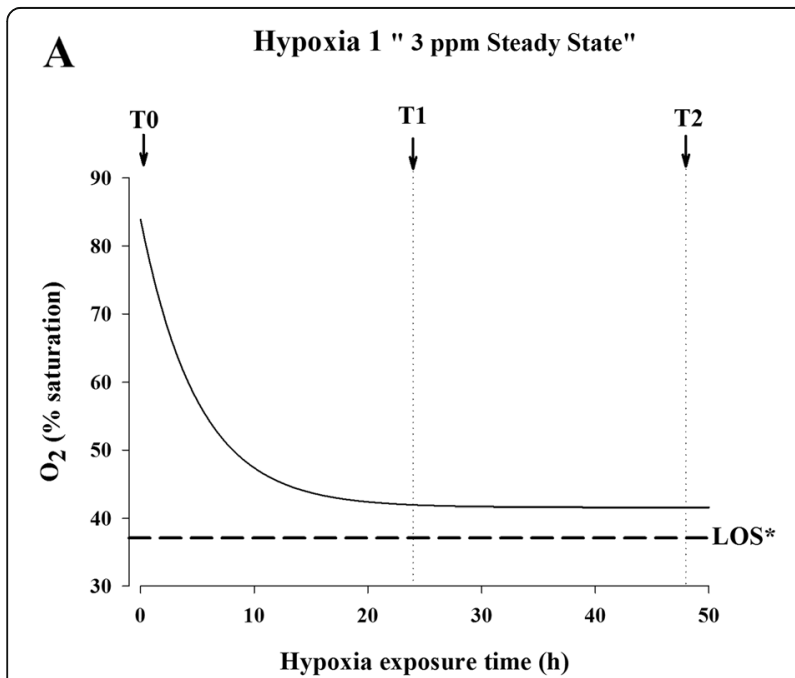

B

Hypoxia 2 " 1.3 ppm Steady State"

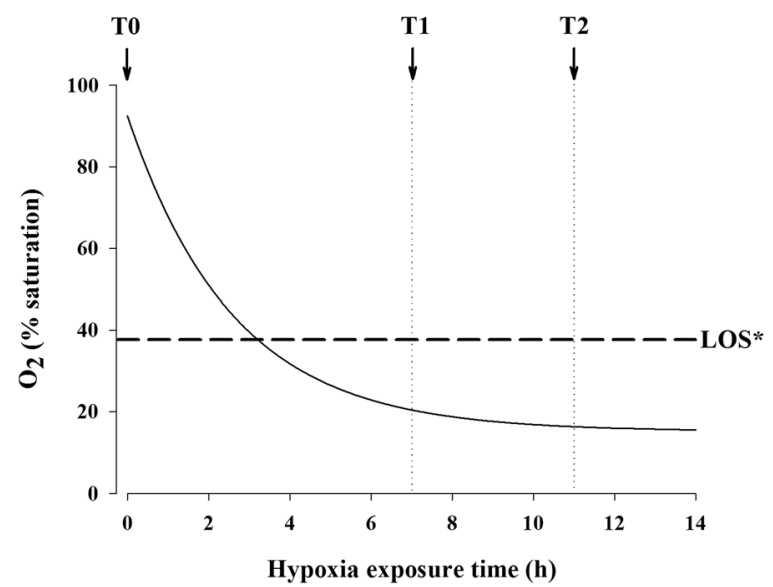

Fig. 1 Water $\mathrm{O}_{2}$ kinetics in fish exposed to hypoxic conditions. The steady-state was set at (a) $41-42 \% \mathrm{O}_{2}$ saturation (3 ppm) or (b) 18-19\% $\mathrm{O}_{2}$ saturation (1.3 ppm). Sampling points (T0, $\mathrm{T} 1$ and $\mathrm{T} 2$ ) are indicated with arrowheads. LOS was calculated according to Remen et al. [5]
The remaining blood was centrifuged at $3000 \times g$ for $20 \mathrm{~min}$ at $4{ }^{\circ} \mathrm{C}$, and the plasma samples were frozen and stored at $-20{ }^{\circ} \mathrm{C}$ until biochemical and hormonal analyses were performed.

\section{Blood biochemistry and hormonal parameters}

Hc was measured using heparinised capillary tubes centrifuged at $1500 \times g$ for $30 \mathrm{~min}$ in a Sigma 1-14 centrifuge (Sigma, Osterode am Harz, Germany). The $\mathrm{Hb}$ concentration was assessed using a Hemocue $\mathrm{Hb} 201+$ (Hemocue, Ängelholm, Sweden). Plasma glucose was analysed using the glucose oxidase method (Thermo Electron, Louisville, CO, USA). Blood lactate was measured in deproteinised samples (perchloric acid 8\%) using an enzymatic method based on the use of lactate dehydrogenase (Instruchemie, Delfzijl, The Netherlands). Total antioxidant capacity in plasma samples was measured using a commercial kit (Cayman Chemical, Ann Arbor, MI, USA) adapted to 96-well microplates. This assay relies on the ability of the antioxidants in the samples to inhibit the oxidation of ABTS (2,2' -azino-di-[3ethylbenzothiazoline sulphonate]) to the ABTS radical cation by metamyoglobin, a derivatised form of myoglobin. The capacity of the sample to prevent ABTS oxidation was compared with that of Trolox (water-soluble tocopherol analogue) and quantified as $\mathrm{mM}$ Trolox equivalents. Plasma cortisol levels were analysed using an EIA kit (Kit RE52061 m IBL, International GmbH, Germany). The limit of detection of the assay was $2.46 \mathrm{ng} / \mathrm{mL}$ with intra- and inter-assay coefficients of variation lower that $3 \%$ and $5 \%$, respectively. Plasma insulin-like growth factors (Igf) were extracted using acid-ethanol cryoprecipitation [21], and the concentration was measured using a generic fish Igf-I RIA validated for Mediterranean perciform fish [22]. The sensitivity and midrange of the assay were 0.05 and $0.7-$ $0.8 \mathrm{ng} / \mathrm{mL}$, respectively.

\section{Gene expression analysis}

Total RNA from total blood cells was extracted using the REAL Total RNA Spin Blood Kit (Durviz) including a DNase step. The RNA yield was $>2.5 \mu \mathrm{g}$, with absorbance measures $\left(\mathrm{A}_{260 / 280}\right)$ of 1.9-2.1. The cDNA was synthesised using the High-Capacity cDNA Archive Kit (Applied Biosystems, Foster City, CA, USA) with random decamers and $500 \mathrm{ng}$ of total RNA in a final volume of $100 \mu \mathrm{L}$. Reverse transcription (RT) reactions were incubated for $10 \mathrm{~min}$ at $25{ }^{\circ} \mathrm{C}$ and $2 \mathrm{~h}$ at $37{ }^{\circ} \mathrm{C}$. Negative control reactions were run without the RT enzyme. qPCR was performed using an Eppendorf Mastercycler Ep Realplex Real-Time Detection System (Eppendorf, Wesseling-Berzdorf, Germany). Diluted RT reactions were conveniently used for $\mathrm{qPCR}$ assays in $25 \mu \mathrm{L}$ volume in combination with a SYBR Green Master 
Mix (Bio-Rad, Hercules, CA, USA) and specific primers at a final concentration of $0.9 \mu \mathrm{M}$ (Additional file 1 : Table S1). The 96-well PCR-array layout was designed for the simultaneous profiling of a panel of 85 mitochondrial genes under uniform cycling conditions and associated with different biological processes, such as molecular chaperones (7), antioxidant defence (8), transcription factors (5), outer and inner membrane translocation (8), mitochondrial dynamics and apoptosis (10), fatty acid oxidation and the tricarboxylic acid cycle (5), OXPHOS (41) and respiration uncoupling (1). The programme used for PCR amplification included an initial denaturation step at $95{ }^{\circ} \mathrm{C}$ for $3 \mathrm{~min}$, followed by 40 cycles of denaturation for $15 \mathrm{~s}$ at $95{ }^{\circ} \mathrm{C}$ and annealing/extension for $60 \mathrm{~s}$ at $60{ }^{\circ} \mathrm{C}$. All the pipetting operations were conducted using an EpMotion $5070 \mathrm{Li}-$ quid Handling Robot (Eppendorf, Hamburg, Germany) to improve data reproducibility. The efficiency of PCRs (>92\%) was assessed, and the specificity of the reactions was verified through an analysis of melting curves (ramping rates of $0.5{ }^{\circ} \mathrm{C} / 10 \mathrm{~s}$ over a temperature range of $55-95{ }^{\circ} \mathrm{C}$ ) and linearity of serial dilutions of the RT reactions $(>0.99)$. Fluorescence data acquired during the extension phase were normalised using the deltadelta $C_{T}$ method [23]. A range of potential housekeeping genes ( $\beta$-actin, cox4a, elongation factor 1, $\alpha$-tubulin and $18 S$ rRNA) was initially tested for gene expression stability using Genorm software. The most stable gene in relation to different experimental conditions (normoxia and hypoxia) was cox4a (M score $=0.31$ ); therefore, this gene was used as the housekeeping gene in the normalisation procedure. For multi-gene analysis, the data on gene expression were in reference to the expression level of sod1 obtained in normoxic fish, for which a value of 1 was arbitrarily assigned (Table 1).

This manuscript follows the ZFIN Zebrafish Nomenclature Guidelines for gene and protein names and symbols (https://wiki.zfin.org/display/general/ZFIN+Zebrafish+Nom enclature+Guidelines).

\section{Statistical analysis}

The data on biochemical and hormonal parameters were analysed using two-way analysis of variance (ANOVA), followed by the Holm-Sidak test. The data on gene expression were analysed using Student's $t$ test. The significance level was set at $P<0.05$. All analyses were performed using SigmaPlot Version 13 for Windows.

\section{Results}

Hypoxic effects on blood haematology and biochemistry Over the course of the first hypoxia test $\left(\mathrm{H} 1,41-42 \% \mathrm{O}_{2}\right.$ saturation), measurements of haematological parameters and plasma glucose and lactate levels remained unaltered in both normoxic ( $>85 \% \mathrm{O}_{2}$ saturation) and hypoxiachallenged fish (Fig. 2a, c, e and g, respectively). In contrast, these parameters significantly increased in fish exposed to severe hypoxia ( $\mathrm{H} 2,18-19 \% \mathrm{O}_{2}$ saturation) (Fig. 2b, d, f and h). The same trend was observed for total plasma antioxidant activity and plasma cortisol levels (Fig. 3a, b), although the cortisol increase was more pronounced at the last sampling point. The opposite regulation was observed for circulating Igf-I, although a statistically significant effect was observed at the last sampling point (Fig. 3c). No variations in all the parameters studied were observed in fish maintained under normoxic conditions in sub-experiment $\mathrm{H} 2$.

\section{Hypoxic effects in whole blood cell gene expression profiling}

Based on the results of hormonal and metabolic parameters, gene expression profiling of whole blood cells was restricted to the last sampling point of the severe hypoxia experiment $(\mathrm{H} 2)$. The relative gene expression and fold-changes (FC) of mitochondrial-related genes are summarised in Table 1. For easier interpretation and visualisation of the results, the FC of differentially expressed genes is indicated using square symbols in red (up-regulated) or green (down-regulated). With the exception of $p g c 1 \alpha$, all the genes included in the array were detected in all samples analysed. Among these genes, 41 out of 84 were differentially expressed, and the overall response involved repressed expression in response to severe hypoxia. This response was mediated by antioxidant enzymes (gpx1, gst3, and sod2), the transcription factor $n r f 1$, outer and inner membrane translocases (tom70, tom22, tim44, tim10, and tim9), markers of mitochondrial dynamics and apoptosis (mfn2, miffb, mirola, miro2, and aifm1), fatty acid $\beta$-oxidation (acaa2 and hadh), tricarboxylic acid cycle (cs), respiration uncoupling (ucp2) and respiratory enzyme subunits of Complex I (ndufa3, ndufa4, ndufa7, ndufb5, and ndufs7), Complex II (sdha, sdhaf1, and sdhaf2), Complex III (uqcrc1, uqcrc2, and uqcrh) and Complex V (atp5c1, atp5g1, atp5l, and atpaf2), encoded by either mitochondrial or nuclear DNA. The nuclear-encoded assembly factors of Complex IV (sco1, surf1, and cox15) were also significantly down-regulated, but the opposite trend was observed for catalytic (coxi) and regulatory (cox5a2 and cox $8 b$ ) enzyme subunits of mitochondrial or nuclear origin, respectively. This up-regulation was also observed for the transcription factor $p g c 1 \beta$ and the outer membrane translocase tom34. The molecular chaperones were the only factors that did not significantly change under hypoxic conditions, although the overall trend was a down-regulation in hypoxic fish. 
Table 1 Relative gene expression of mitochondrial-related genes in total blood cells

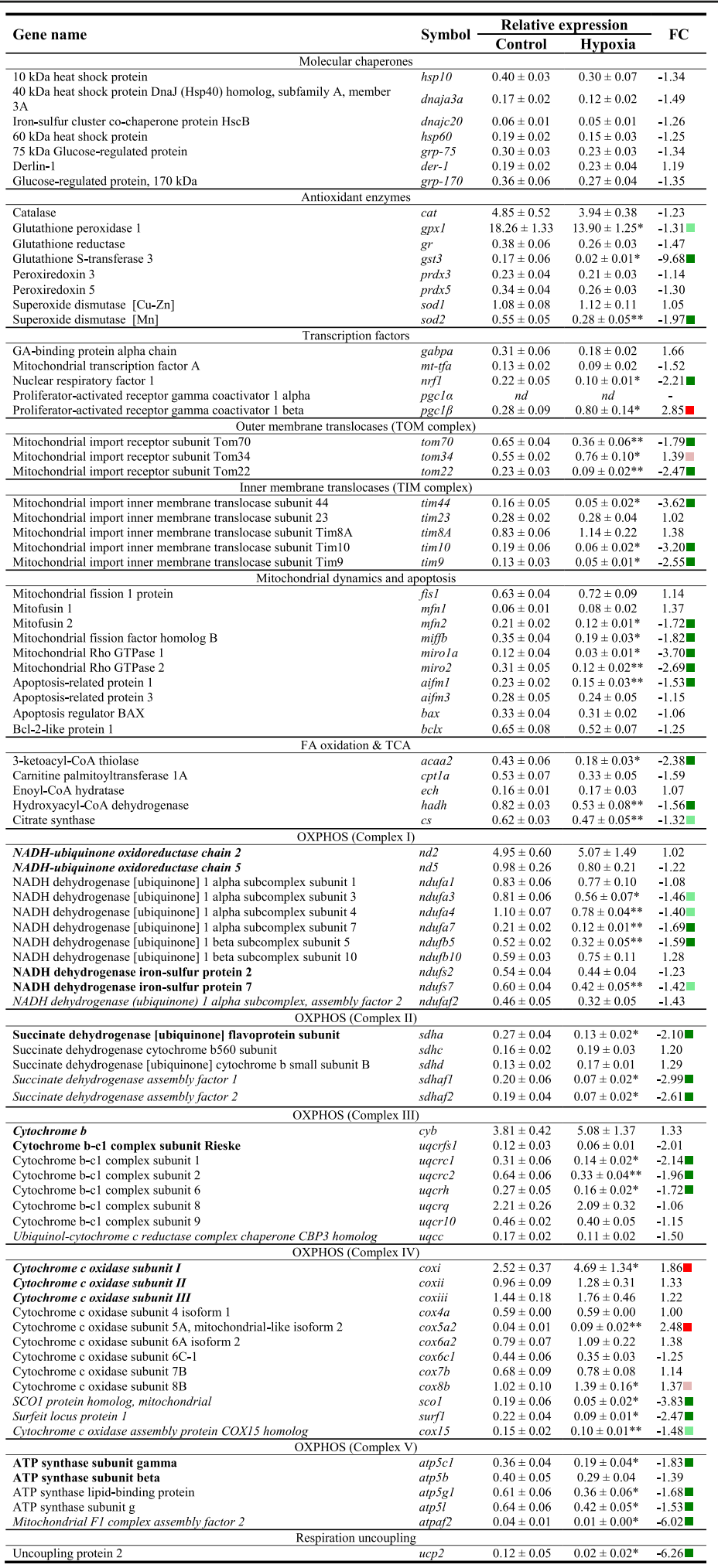

Gilthead sea breams were exposed to normoxic (oxygen saturation $>85 \%$ ) and hypoxic (1.3 ppm, oxygen saturation $=18-19 \%)$ conditions. Data are presented as the mean \pm SEM $(n=7-8)$. Statistically significant differences between normoxic and hypoxic fish are indicated ${ }^{*} P<0.05,{ }^{* *} P<0.01$; Student's $t$ test). nd: non-detected. Gene names of mitochondrial-encoded catalytic subunits of the OXPHOS pathway are highlighted in bold and italicised. Gene names of nuclear-encoded catalytic subunits of the OXPHOS pathway are highlighted in bold. Gene names of nuclear-encoded regulatory subunits are presented in normal font. Gene names of nuclearencoded assembly factors are italicised. Square symbols are used for up- (red) and down-regulated genes (green) 

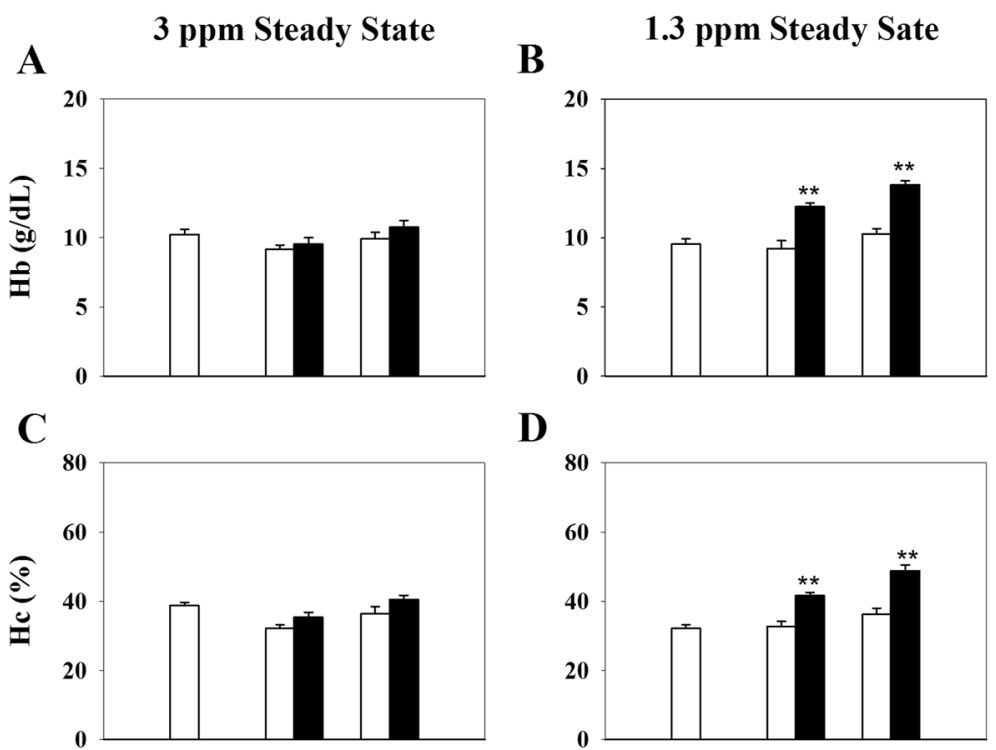

D

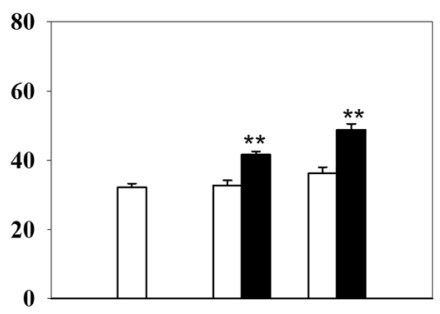

$\mathbf{E}$

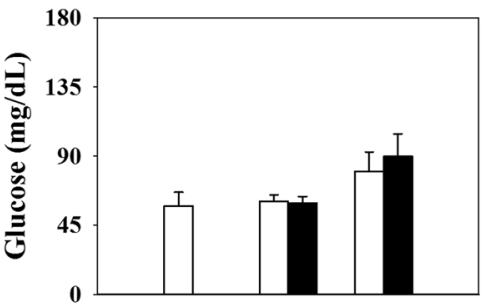

F

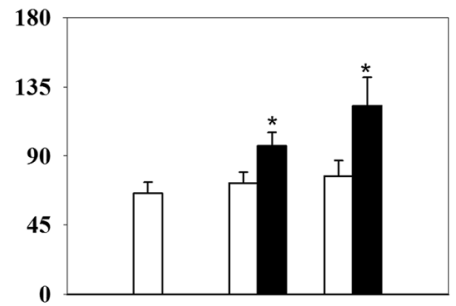

G

$\mathbf{H}$
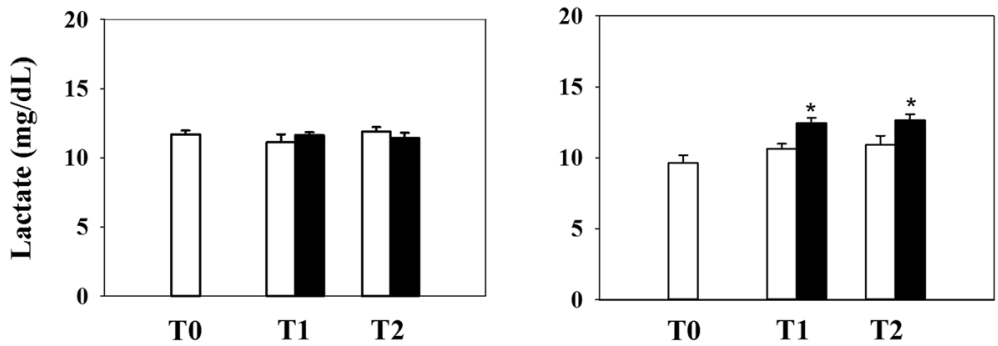

Fig. 2 Effects of normoxia (white bars) and hypoxia (black bars) on blood haematology and biochemistry. Hypoxia levels were set above (a, c, e, g) or below $(\mathbf{b}, \mathbf{d}, \mathbf{f}, \mathbf{h})$ the LOS. Data are presented as the mean \pm SEM $(n=7-8)$. Statistically significant differences between normoxic and hypoxic fish are indicated $\left({ }^{*} P<0.05,{ }^{* *} P<0.01\right.$; two-way analysis of variance (ANOVA) followed by the Holm-Sidak test)

\section{Discussion}

Studies in gilthead sea bream have indicated that the response of this species to a progressive decline in $\mathrm{O}_{2}$ concentration is to reduce its swimming activity, indicative of an increasing metabolic stress and/or a coping strategy to prolong survival time when hypoxia cannot be avoided [5]. In the same study, the threshold level of LOS determined in 400-g fish varied from $17 \% \mathrm{O}_{2}$ saturation at $12^{\circ}$ $\mathrm{C}$ and $36 \% \mathrm{O}_{2}$ saturation at $20{ }^{\circ} \mathrm{C}$. These $\mathrm{O}_{2}$ concentrations can be implemented in aquaculture as a lower limit for acceptable decreases in $\mathrm{O}_{2}$ concentration with respect to the physiological function and welfare of farmed gilthead sea bream. Therefore, as further explained below, it is not surprising that data on blood biochemistry and haematology in fish exposed to $\mathrm{O}_{2}$ concentrations above the LOS did not significantly vary after $24 \mathrm{~h}$ of hypoxia challenge. In contrast, a consistent response, exacerbated over time, was observed for blood parameters measured a few hours after exposure to $\mathrm{O}_{2}$ concentrations below the LOS. In this case, the gene expression profile of whole blood cells was analysed, and the molecular signatures of hypoxic fish revealed important changes consistent with reduced but more efficient aerobic ATP production.

Living organisms are characterised by continuous switching between resting and active states, which includes long resting periods with low ATP production 

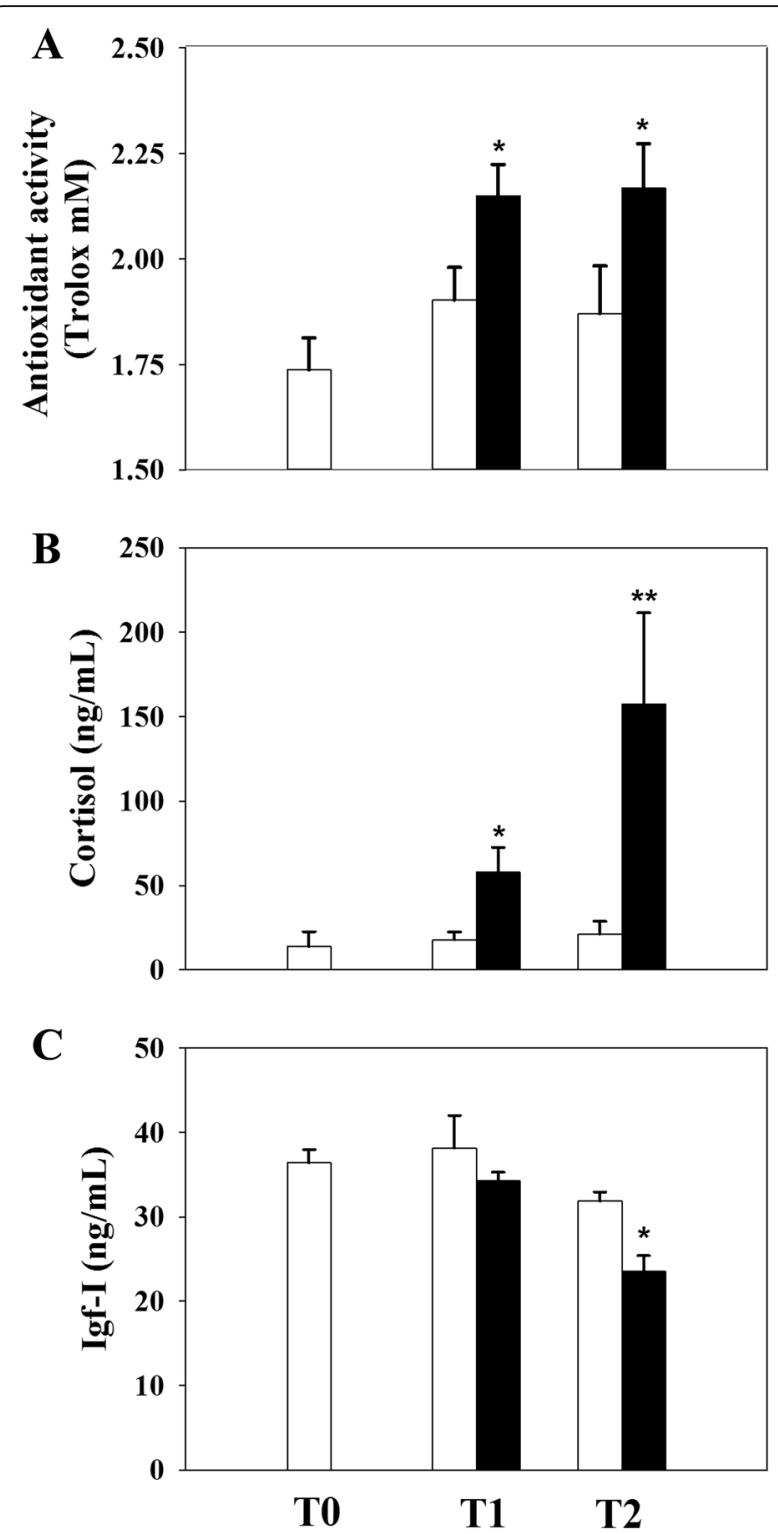

Fig. 3 Effects of normoxia (white bars) and hypoxia (black bars) below the LOS on plasma parameters. Antioxidant activity (a), cortisol (b) and Igf-I (c). Data are presented as the mean \pm SEM $(n=7-8)$. Statistically significant differences between normoxic and hypoxic fish are indicated $\left({ }^{*} P<0.05,{ }^{*} P<0.01\right.$; two-way analysis of variance (ANOVA) followed by the Holm-Sidak test)

[24]. Similarly, the response to hypoxia has two main aspects characterised by defence and rescue, where the early defence stage is achieved by reducing energy needs (hypo-metabolic state) and the dependence on aerobic metabolism [25]. In the case of gilthead sea bream, the antioxidant defences in fish fed diets supplemented with methionine and white tea were insufficient to avoid oxidative stress under moderate hypoxia induced by $40 \%$ $\mathrm{O}_{2}$ saturation at $22-23{ }^{\circ} \mathrm{C}$ [26]. However, LOS increases with decreasing temperature [6], and the results of the present study showed that all measured haematological and biochemical parameters remained mostly unaltered in fish maintained at $20-21{ }^{\circ} \mathrm{C}$ and $41-42 \% \mathrm{O}_{2}$ saturation. In contrast, a pronounced increase in $\mathrm{Hc}, \mathrm{Hb}$ and plasma glucose and lactate levels was reported after exposure to severe hypoxia (18-19\% $\mathrm{O}_{2}$ saturation) for $4 \mathrm{~h}$ under steady-state conditions. Indeed, this rapid response could reflect an increase in blood $\mathrm{O}_{2}$-carrying capacity [27] associated in the short term with erythrocyte release from a storage organ or with a reduction in plasma volume rather than the formation of new $\mathrm{Hb}$ [28]. Consistent with [8], this finding likely reflects metabolic changes mediated by $\mathrm{O}_{2}$ sensors that drive the shift of the redox cellular status of NADH to a more reduced form with a rapid recycling of $\mathrm{NAD}^{+}$to NADH. Certainly, hypoxic situations must improve and adjust the metabolic and $\mathrm{O}_{2}$-carrying capacities of challenged fish to cope and reach internal homeostasis [29]. The trigger observed in plasma antioxidant capacity after acute and severe hypoxia demonstrates a general decrease in metabolic rates that also reflects the aerobic/ anaerobic shift of metabolism [25, 30,31].

The increase in plasma cortisol levels observed after severe hypoxia indicates a stressful scenario in the experimental model used in the present study. Other common features of hypoxic and stress conditions include a decrease in plasma Igf-I levels and concomitant growth inhibition [32, 33]. In this sense, a characteristic response in challenged gilthead sea bream produced by crowding, and presumably also through hypoxia, is the overall downregulated expression of hepatic igfs and growth hormone receptors [34]. Studies in rodents support the involvement of the Gh/Igf system in the regulation of key antioxidant enzymes, ROS production and scavenging as well mitochondrial biogenesis and activity $[35,36]$. However, thus far, the precise mechanisms underlying these Gh/Igf-mediated effects remain unexplored in fish. Moreover, confounding results have been reported for the aerobic/ anaerobic shift during hypoxia exposure, although studies in the euryoxic mudsucker Gillichthys mirabilis showed a tissue-specific gene regulation resulting in suppressed protein synthesis in skeletal muscle and enhanced anaerobic ATP production in the liver tissue [14]. Similarly, zebra fish (Danio rerio) embryos survive during severe hypoxia $\left(0-5 \% \mathrm{O}_{2}\right.$ saturation) through changes in the gene and protein expression of master regulators of $\mathrm{O}_{2}$ homeostasis, such as the hypoxia-inducible factor 1 alpha (hif- $1 \alpha / \mathrm{Hif}-$ $1 \alpha$ ) [37-40]. Additionally, long-term adaptive responses in the gene expression of several pathways related to cell architecture, cell division and energy metabolism have been underlined in the gills of adult hypoxic fish [41]. In our experimental model, this hypothesis was perfectly consistent with hypoxic-mediated effects on mitochondrial-related markers of blood cells (see below). 
Most mitochondrial proteins are encoded by nuclear DNA; thus, a healthy metabolic mitochondria phenotype is highly dependent on the protein import system, which involves two assembly complexes: the translocases of the outer membrane (TOM complex) and the translocases of the inner membrane (TIM complex) (see [42, 43] for review). Thus, as demonstrated in mammalian cells [44], the TOM/TIM complex is highly inducible and regulated at both transcriptional and post-transcriptional levels under conditions of chronic stress or energy deficit to ensure the maintenance of adequate mitochondrial protein import rates. Similarly, juveniles of gilthead sea bream exhibit a clear up-regulation in the gene expression of hepatic protein subunits of the TOM/TIM complex in response to aerobic energy stimuli after exposure to cyclic decreases in water temperature [20]. Conversely, the present study demonstrated that severe hypoxia induced a pronounced down-regulation of tom70 and tom 22 subunits in whole blood cells concurrent with decreases in mRNAs encoding protein subunits of TIM23 (tim44) and TIM22 (tim10 and tim9) complexes. In addition, co-expression analyses revealed the up-regulation of tom34, which acts as a cochaperone of the Hsp70/Hsp90 complex, inhibiting mitochondrial protein translocation when expressed in excess [45]. Taken together, these findings suggest in hypoxic fish an orchestration of the TOM/TIM complex that could enable adjustments in mitochondrial protein translocation to reduce plasma oxidative capacity and the risk of oxidative stress, a feature that is consistent with the down-regulated expression of markers of ROS production and scavenging, including $u c p 2$, mitochondrial superoxide dismutase $(\operatorname{sod} 2)$, enzymes of the glutathione system (gpx1 and gst3) and enzymes of fatty acid $\beta$-oxidation and TCA (acaa2, hadh, and cs). Importantly, the same trend was observed for mitochondrial ( $h s p 10$, dnaja3a, dnajc20, hsp60, and grp-75) and endoplasmic reticulum (grp-170) molecular chaperones, suggesting that proper protein folding was primarily assured in the blood cells of gilthead sea bream under the depressed metabolism induced by hypoxia exposure. Similarly, severe hypoxia did not induce the gene expression of heat shock proteins in rainbow trout (Oncorhynchus mykiss) RBCs cultured in vitro when the hypoxia challenge was not accompanied by a heat shock treatment [46].

Mitochondrial dynamics is an essential process that adapts mitochondria morphology to the bioenergetics requirements of the cell (see [47] for review). The mechanism of this biological process involves the balance of two opposing procedures (fusion and fission), but it is also greatly affected by the "railways" used by the mitochondria to move inside the cells. The functionality of these organelles favours the redistribution of mitochondria within the cell to ensure high oxidative capacity under conditions of high energy demand, enabling the removal of dysfunctional or damaged mitochondria. This mechanism is highly conserved from yeast to mammals [48], and the molecular identity of major components of the fusion ( $m f n 1$ and $m f n 2$ ) and fission (fis1 and miffb) system, as well as those of the MIRO system (mirola and miro2) has been characterised in gilthead sea bream and uploaded to public database repositories [20]. Nevertheless, experimental evidences demonstrated that the gene expression of some of these effectors is highly induced in response to aerobic stimuli after cold-water exposure. In contrast, in the present study, severe hypoxia significantly repressed the expression of most components of this biological process ( $m f n 2$, miffb, miro1a, and miro2), including the well-known mitochondrial apoptotic factor aifm1. Consistently, the knockout of the transcriptional regulator $p g c 1 \beta$ is associated with a selective reduction in the expression in mice [49]. The lack of Pgc1 $\beta$ also impaired the thermogenic response of adipose tissue and hepatic lipid metabolism in response to high fat dietary loads [50]. Therefore, $\operatorname{Pgc} 1 \beta$ is essential for proper metabolic tuning in stress situations, contributing to the maintenance of the basal expression of mitochondrial and metabolic-related genes. However, in the present experimental model, the opposite regulation was observed for $p g c 1 \beta$ and $m f n 2$, suggesting that the up-regulated expression of $p g c 1 \beta$ was more a consequence than the cause of the overall repressed expression of mitochondria-related genes. This notion was supported by the observation that the mitochondrial transcription factor $n r f 1$, another target gene of $p g c 1 \beta$ [50], was also down-regulated in hypoxia-challenged fish. Notably, despite the overlapping gene expression of pgc1 $\beta$ and its homologue pgc1 $\alpha$, the compensation of Pgc1 $\alpha$ or Pgc1ß functions was not completely observed in Pgc1 $\alpha$ or Pgc1ß knockout rodents [51-53]. In the case of gilthead sea bream blood cells, this effect is more exacerbated because $p g c 1 \alpha$ mRNAs were almost undetectable in both normoxic and hypoxic fish, although the expression of this gene at noticeable levels has previously been reported in other tissues of this fish species [20]. Whether this effect is part of the evolutionary pressure to select the conservation of functional mitochondria in the nucleated RBCs of non-mammalian vertebrates remains to be established [17].

The ultimate effector for coping with changes in energy needs and aerobic ATP production is the regulation of the OXPHOS pathway, which comprises five enzyme complexes (I-V) with catalytic enzymatic subunits encoded by both nuclear or mitochondrial DNA, whereas the enzyme subunits with regulatory or assembly properties are strictly of nuclear origin [19]. Changes in the enzymatic activities of the OXPHOS pathway have been studied for many years both in mammals and fish 
(e.g., [54-56]). Little is known at the molecular level, although gene expression profiling of liver, skeletal muscle and cardiac muscle tissues revealed that both the direction and magnitude of change is highly dependent on the metabolic capabilities of each tissue [8]. Thus far, the molecular fingerprinting of the OXPHOS pathway remains primarily unexplored in blood cells, and this is the first to address the specific regulation of this pathway in response to environmental stressors, evidenced by the general depletion of several components of Complexes I, II, III and V in response to severe hypoxic stimuli. Assembly factors of Complex IV (sco1, surf1 and cox15) were also down-regulated in the present experimental model. These enzyme subunits play an important role in energy production, and mutations or defects in these molecules produce adverse effects in the appropriate function of the OXPHOS pathway in mammals [57-61]. However, this observation contrasted with the overall overexpression of catalytic and regulatory subunits of Complex IV, which was statistically significant for the catalytic coxi and the regulatory cox $5 a 2$ and cox $8 b$ subunits. CoxI protein is encoded by mitochondrial DNA and represents one of the largest subunits of Complex IV, which contains the bimetallic centre where $\mathrm{O}_{2}$ binds and is reduced to $\mathrm{H}_{2} \mathrm{O}[62,63]$. In addition, the observed increase in the gene expression of Cox $5 \mathrm{a}$ and Cox 8 family subunits highlights their importance during the completion of the holocomplex monomer, which contains the functional structure of the cytochrome $c$ binding site (see [64] for review). Therefore, we hypothesised that the net effect should be a reduced mitochondrial ATP production due to the overall suppression of mRNAs encoding the enzyme subunits of Complexes I, II, III and IV, although the opposite regulation of the catalytic/regulatory components of Complex IV should be accompanied by subsequent mechanisms that allow a better exploitation of available oxygen in the most energetically favorable way. Modifications in mitochondrial properties also occur in other vertebrates, and the hypo-metabolic steady-state observed in overwintering frogs (Rana temporaria) occurred during hypoxic submergence by increases in mitochondrial $\mathrm{O}_{2}$ affinity and a reduction in resting (state 4 ) and active (state 3 ) respiration rates in mitochondria isolated from skeletal muscle [65]. Similarly, early studies in the freshwater European eel (Anguilla anguilla) suggest that the efficiency of OXPHOS is increased after acclimation to high hydrostatic pressure, decreasing the enzymatic activity of Complex II in red muscle, whereas that of Complex IV is significantly increased [66]. This situation would enable a reduction in the electron leak and the optimisation of the respiratory chain. Similarly, more recent studies in gilthead sea bream have revealed that the gene expression ratio of the enzyme subunits of Complexes I and IV is altered in heart and liver tissue during the recovery state after severe hypoxia exposure [67]. Thus, as reviewed by [68], it is now evident that variations in the mitochondrial efficiency of ATP production exist among individuals, populations and environments, and even within the same individual over time. This spatial and temporal variability in mitochondrial machinery adds an

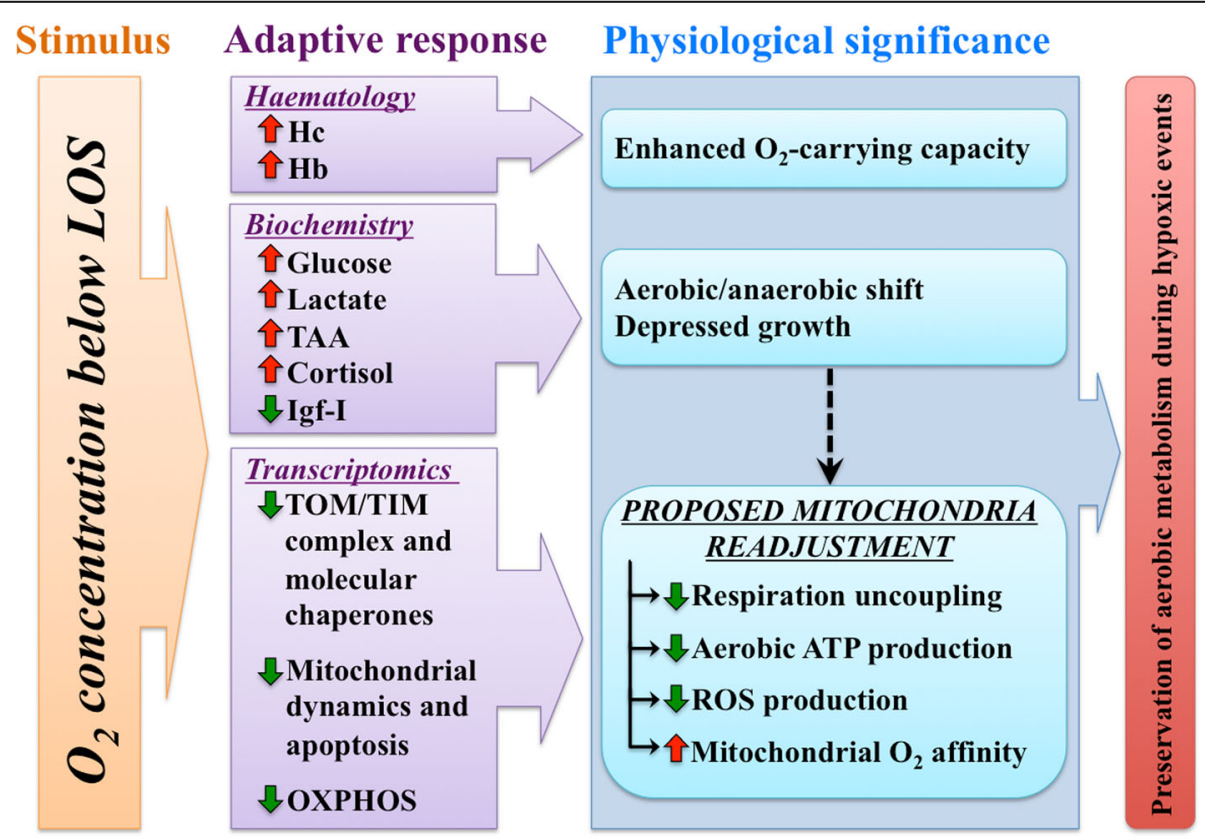

Fig. 4 Schematic representation of the proposed model for integrative physiological responses of gilthead sea bream exposed to acute and severe hypoxia 
additional layer of complexity to the regulation of energy metabolism, and the maintenance of aerobic metabolism is becoming recognised as a primary hypoxia survival strategy in most organisms, including fish [69]. Even so, the usage of transcriptomic analysis with other experimental approaches related to mitochondrial activity and respiration would be necessary for the better understanding about the proposed re-adjustment of mitochondrial function in hypoxia-challenged fish.

\section{Conclusions and future perspectives}

As summarized in Fig. 4, the integrated data on blood haematology, biochemistry and transcriptomics in response to water $\mathrm{O}_{2}$ concentrations below the LOS highlighted an enhanced $\mathrm{O}_{2}$-carrying capacity as a result of higher $\mathrm{Hc}$ and $\mathrm{Hb}$ concentrations in response to strong hypoxic stimuli. Changes in plasma antioxidant capacity, as well as hormone and metabolite levels supported reduced energy needs and also reflected an aerobic/anaerobic shift. These results were further confirmed by gene expression profiling of a wide representation of mitochondrial-related markers, including antioxidant enzymes and molecular chaperones, effectors of mitochondrial dynamics and apoptosis, and key components of the respiratory chain, suggesting that the mitochondrial bioenergetics of fish blood cells are finely adjusted at the transcriptional level through changes in water $\mathrm{O}_{2}$ concentrations. The induced gene expression profiles of catalytic and regulatory enzyme subunits of Complex IV should be considered an adaptive process to ensure reduced but more efficient aerobic ATP production consistent with reduced respiration uncoupling, as suggested by the decreased expression of $u c p 2$. These results indicate that the gilthead sea bream is a highly euryoxic fish. Further studies are underway to determine the resilience of gilthead sea bream to high rearing densities and low $\mathrm{O}_{2}$ concentrations, exploring the potential benefits of hypoxic preconditioning for improving the aerobic scope and swimming metabolic activity of farmed fish.

\section{Additional file}

Additional file 1: Table S1. Forward (F) and reverse (R) primers used for real-time PCR. (DOCX $50 \mathrm{~kb}$ )

\footnotetext{
Acknowledgements

The authors are grateful to M.A. González for her excellent technical assistance with sampling and PCR analyses.
}

\section{Funding}

This work was financially supported by a grant from the European Commission of the European Union under the Horizon 2020 research infrastructure project AQUAEXCEL ${ }^{2020}$ (652831). Additional funding was provided by Generalitat Valenciana (PROMETEOI//2014/085). JAMS received a Postdoctoral Research Fellowship (Juan de la Cierva-Formación, Reference FJCI-2014-20,161) from MINECO.

\section{Availability of data and materials}

The datasets supporting the conclusions of this study are included within the article and its additional Supporting Information file.

\section{Authors' contributions}

JACG and JPS conceived and designed the study. ABN, JACG and JAMS performed the experimental procedures. JAMS, JACG and JPS analysed and interpreted the data. JAMS and JPS drafted the original manuscript. All authors reviewed, edited and approved the final manuscript.

\section{Ethics approval}

All procedures were approved by the Ethics and Animal Welfare Committee of Institute of Aquaculture Torre de la Sal and carried out according to the National (Royal Decree RD53/2013) and the current EU legislation (2010/63/ EU) on the handling of experimental fish.

Consent for publication

Not applicable.

\section{Competing interests}

The authors declare that they have no competing interests.

\section{Publisher's Note}

Springer Nature remains neutral with regard to jurisdictional claims in published maps and institutional affiliations.

\section{Author details}

${ }^{1}$ Nutrigenomics and Fish Growth Endocrinology Group, Institute of Aquaculture Torre de la Sal, Consejo Superior de Investigaciones Científicas (IATS-CSIC), Ribera de Cabanes, E-12595 Castellón, Spain. ${ }^{2}$ Present address: Endocrine Disruption and Toxicity of Contaminants, Department of Environment, INIA, Madrid, Spain.

Received: 4 April 2017 Accepted: 28 June 2017

Published online: 06 July 2017

\section{References}

1. Fry FEJ. Effects of the environment on animal activity. Univ Tor Stud Biol Ser. 1947;68:5-62.

2. Fry FEJ. The effect of environmental factors on the physiology of fish. In: Hroar WS, Randall DJ, editors. Fish physiology. Environmental relations and behavior 6. New York: Academic Press, Elsevier; 1971. p. 1-87.

3. Pörtner HO, Grieshaber MK. Critical PO2 (s) in oxyconforming and oxyregulating animals gas exchange, metabolic rate and the mode of energy production. In: Bicudo JEPW, editor. The vertebrate gas transport cascade adaptations to environment and mode of life. Boca Raton: CRC Press; 1993. p. 330-57.

4. Saravanan S, Geurden I, Figueiredo-Silva AC, Kaushik SJ, Haidar MN, Verreth JA, Schrama JW. Control of voluntary feed intake in fish: a role for dietary oxygen demand in Nile tilapia (Oreochromis niloticus) fed diets with different macronutrient profiles. Br J Nutr. 2012;108:1519-29.

5. Remen M, Nederlof MAJ, Folkedal O, Thorsheim G, Sitjà-Bobadilla A, PérezSánchez J, Oppedal F, Olsen RE. Effect of temperature on the metabolism, behavior and oxygen requirements of Sparus aurata. Aquacult Env Interac. 2015;7:115-23.

6. Remen M, Sievers M, Torgersen T, Oppedal F. The oxygen threshold for maximal feed intake of Atlantic salmon post-smolts is highly temperaturedependent. Aquaculture. 2016:464:582-92

7. Lushchak VI, Bagnyukova TV. Effects of different environmental oxygen levels on free radical processes in fish. Comp Biochem Physiol B-Biochem Mol Biol. 2006;144:283-9.

8. Bermejo-Nogales A, Calduch-Giner JA, Pérez-Sánchez J. Tissue-specific gene expression and functional regulation of uncoupling protein 2 (UCP2) by hypoxia and nutrient availability in gilthead sea bream (Sparus aurata): implications on the physiological significance of UCP1-3 variants. Fish Physiol Biochem. 2014;40:751-62.

9. Khacho M, Tarabay M, Patten D, Khacho P, MacLaurin JG, Guadagno J, Bergeron R, Cregan SP, Harper M-E, Park DS, Slack RS. Acidosis overrides oxygen deprivation to maintain mitochondrial function and cell survival. Nat Commun. 2014;5:3550. 
10. Hoppeler H, Vogt M. Muscle tissue adaptations to hypoxia. J Exp Biol. 2001; 204:3133-9.

11. Murray AJ. Metabolic adaptation of skeletal muscle to high altitude hypoxia: how new technologies could resolve the controversies. Genome Med. 2009; 1:117

12. Gamboa JL, Andrade FH. Muscle endurance and mitochondrial function after chronic normobaric hypoxia: contrast of respiratory and limb muscles. Pflug Arch Eur J Physiol. 2012;463:327-38.

13. Donohoe PH, West TG, Boutilier RG. Respiratory, metabolic and acid-base correlates of aerobic metabolic rate reduction in overwintering frogs. Am J Physiol-Reg I. 1998;43:R704-10

14. Gracey AY, Troll JV, Somero GN. Hypoxia-induced gene expression profiling in the euryoxic fish Gillichthys mirabilis. Proc Natl Acad Sci U S A. 2001;98: 1993-8.

15. Everett MV, Antal CE, Crawford DL. The effect of short-term hypoxic exposure on metabolic gene expression. J Exp Zool Part A. 2012;317:9-23.

16. Vanderplancke $G$, Claireaux $G$, Quazuguel $P$, Madec L, Ferraresso $S$, Sévère $A$, Zambonino-Infante JL, Mazurais D. Hypoxic episode during the larval period has long-term effects on European sea bass juveniles (Dicentrarchus labrax). Mar Biol. 2015;162:367-76.

17. Stier A, Bize P, Schull Q, Zoll J, Singh F, Geny B, Gros F, Royer C, Massemin S, Criscuolo F. Avian erythrocytes have functional mitochondria, opening novel perspectives for birds as animal models in the study of ageing. Front Zool. 2013;10:33

18. Calduch-Giner JA, Echasseriau Y, Crespo D, Baron D, Planas JV, Prunet $P$, Pérez-Sánchez J. Transcriptional assessment by microarray analysis and large-scale meta-analysis of the metabolic capacity of cardiac and skeletal muscle tissues to cope with reduced nutrient availability in gilthead sea bream (Sparus aurata L.). Mar Biotechnol. 2014;16:423-35.

19. Bermejo-Nogales A, Calduch-Giner JA, Pérez-Sánchez J. Unraveling the molecular signatures of oxidative phosphorylation to cope with the nutritially changing metabolic capabilities of liver and muscle tissues in farmed fish. PLoS One. 2015;10(4):e0122889.

20. Bermejo-Nogales A, Nederlof M, Benedito-Palos L, Ballester-Lozano GF, Folkedal O, Olsen RE, Sitjà-Bobadilla A, Pérez-Sánchez J. Metabolic and transcriptional responses of gilthead sea bream (Sparus aurata) to environmental stress: new insights in fish mitochondrial phenotyping. Gen Comp Endocrinol. 2014a;205:305-15.

21. Shimizu M, Swanson P, Fukada H, Hara A, Dickhoff WW. Comparison of extraction methods and assay validation for salmon insulin-like growth factor-I using commercially available components. Gen Comp Endocrinol. 2000;119:26-36.

22. Vega-Rubín de Celis S, Gómez-Requeni P, Pérez-Sánchez J. Production and characterization of recombinantly derived peptides and antibodies for accurate determinations of somatolactin, growth hormone and insulin-like growth factor-l in European sea bass (Dicentrarchus labrax). Gen Comp Endocrinol. 2004;139:266-77.

23. Livak KJ, Schmittgen TD. Analysis of relative gene expression data using real-time quantitative $P C R$ and the $2^{-\Delta \Delta C t}$ method. Methods. 2001;25:402-8.

24. Kadenbach B, Ramzan R, Wen L, Vogt S. New extension of the Mitchell theory for oxidative phosphorylation in mitochondria of living organism. BBA-Gen Subj. 1800;2010:205-12.

25. Hochachka PW, Buck LT, Doll CJ, Land SC. Unifying theory of hypoxia tolerance: molecular/metabolic defense and rescue mechanisms for surviving oxygen lack. Proc Natl Acad Sci U S A. 1996;93:9493-8.

26. Pérez-Jiménez A, Peres $H$, Rubio VC, Oliva-Teles A. The effect of hypoxia on intermediary metabolism and oxidative status in gilthead sea bream (Sparus aurata) fed on diets supplemented with methionine and white tea. Comp Biochem Physiol C-Toxicol Pharmacol. 2012:155:506-16.

27. Wood SC, Johansen K. Adaptation to hypoxia by increased $\mathrm{HbO}_{2}$ affinity and decreased red cell ATP concentration. Nat New Biol. 1972;237:278-9.

28. Soivio A, Nikinmaa M, Westman K. The blood oxygen binding properties of hypoxic Salmo gairdneri. J Comp Physiol. 1980;136(1):83-7.

29. Storey KB. Regulation of hypometabolism: insights into epigenetic controls. J Exp Biol. 2015;218(1):150-9.

30. Dalla Via J, Van den Thillart G, Cattani O, Cortesi P. Behavioural responses and biochemical correlates in Solea solea to gradual hypoxic exposure. Can J Zool. 1998:76:2108-13.

31. Virani NA, Rees BB. Oxygen consumption, blood lactate and inter-individual variation in the gulf killifish, Fundulus grandis, during hypoxia and recovery. Comp Biochem Physiol A-Mol Integr Physiol. 2000;126:397-405.
32. Mommsen TP, Vijayan MM, Moon TW. Cortisol in teleosts: dynamics, mechanisms of action, and metabolic regulation. Rev Fish Biol Fish. 1999;9: 211-68.

33. Dyer AR, Upton Z, Stone D, Thomas PM, Soole KL, Higgs N, Quinn K, Carragher JF. Development and validation of a radioimmunoassay for fish insulin-like growth factor I (IGF-I) and the effect of aquaculture related stressors on circulating IGF-I levels. Gen Comp Endocrinol. 2004;135:268-75.

34. Saera-Vila A, Calduch-Giner JA, Prunet P, Pérez-Sanchez J. Dynamics of liver GH/IGF axis and selected stress markers in juvenile gilthead sea bream (Sparus aurata) exposed to acute confinement: differential stress response of growth hormone receptors. Comp Biochem Physiol A-Mol Integr Physiol. 2009;154:197-203.

35. Brown-Borg HM, Rakoczy SG, Romanick MA, Kennedy MA. Effects of growth hormone and insulin like growth factor-1 on hepatocyte antioxidative enzymes. Exp Biol Med. 2002;227:94-104.

36. Brown-Borg HM, Rakoczy SG. Growth hormone administration to long-living dwarf mice alters multiple components of the antioxidative defense system. Mech Aging Dev. 2003;124:1013-24.

37. Ton C, Stamatiou D, Liew CC. Gene expression profile of zebrafish exposed to hypoxia during development. Physiol Genomics. 2003;13:97-106.

38. Woods IG, Imam FB. Transcriptome analysis of severe hypoxic stress during development in zebrafish. Genomics data. 2015;6:83-8.

39. Robertson CE, Wright PA, Köblitz L, Bernier NJ. Hypoxia-inducible factor-1 mediates adaptive developmental plasticity of hypoxia tolerance in zebrafish, Danio rerio. P Royal Soc Lond B Bio. 2014;281(1786):20140637.

40. Köblitz L, Fiechtner B, Baus K, Lussnig R, Pelster B. Developmental expression and hypoxic induction of hypoxia inducible transcription factors in the zebrafish. PLoS One. 2015;10(6):e0128938.

41. van der Meer DL, van den Thillart GE, Witte F, de Bakker MA, Besser J, Richardson MK, Spaink HP, Leito JTD, Bagowski CP. Gene expression profiling of the long-term adaptive response to hypoxia in the gills of adult zebrafish. Am J Physiol-Reg I. 2005;289:1512-9.

42. Pfanner N, Meijer M. Mitochondrial biogenesis: the tom and Tim machine. Curr Biol. 2010;7:100-3.

43. Smits P, Smeitink J, van den Heuvel L. Mitochondrial translation and beyond: processes implicated in combined oxidative phosphorylation deficiencies. J Biomed Biotechnol. 2010;2010:737385.

44. Ljubicic V, Joseph AM, Saleem A, Uguccioni G, Collu-Marchese M, Lai RY, Nguyen LM-D, Hood D. A. Transcriptional and post-transcriptional regulation of mitochondrial biogenesis in skeletal muscle: effects of exercise and aging. BBA-Gen Subj. 2010;1800:223-34.

45. Faou P, Hoogenraad NJ. Tom34: a cytosolic cochaperone of the Hsp90/ Hsp70 protein complex involved in mitochondrial protein import. BBA-Mol Cell Res. 2012;1823:348-57.

46. Currie $\mathrm{S}$, Tufts BL, Moyes CD. Influence of bioenergetic stress on heat shock protein gene expression in nucleated red blood cells of fish. Am J of Physiol-Reg I. 1999;276:990-6.

47. Ferree $A$, Shirihai $O$. Mitochondrial dynamics: the intersection of form and function. In: Kadenbach B, editor. Mitochondrial oxidative Phosphorylation. New York: Springer; 2012. p. 13-40.

48. Anesti V, Scorrano L. The relationship between mitochondrial shape and function and the cytoskeleton. BBA-Bioenerg. 2006;1757:692-9.

49. Liesa M, Borda-d'Água B, Medina-Gómez G, Lelliott CJ, Paz JC, Rojo M, Palacín M, Vidal-Puig A, Zorzano A. Mitochondrial fusion is increased by the nuclear coactivator PGC-1ß. PLoS One. 2008;3(10):e3613.

50. Patti ME, Butte AJ, Crunkhorn S, Cusi K, Berria R, Kashyap S, Miyazaki Y, Kohane I, Costello M, Saccone R, Landaker EJ, Goldfine AB, Mun E, DeFronzo R, Finlayson J, Kahn CR, Mandarino L. Coordinated reduction of genes of oxidative metabolism in humans with insulin resistance and diabetes: potential role of PGC1 and NRF1. P Nat Acad Sci USA. 2003;100:8466-71.

51. Arany Z, He H, Lin J, Hoyer K, Handschin C, Toka O, Ahmad F, Matsui T, Chin S, Wu P-H, Rybkin II, Shelton JM, Manieri M, Cinti S, Schoen FJ, Bassel-Duby R, Rosenzweig A, Ingwall JS, Spiegelman BM. Transcriptional coactivator PGC-1a controls the energy state and contractile function of cardiac muscle. Cell Metab 2005;1:259-271.

52. Leone TC, Lehman JJ, Finck BN, Schaeffer PJ, Wende AR, Boudina S, Courtois M, Wozniak DF, Sambandam N, Bernal-Mizrachi C, Chen Z, Holloszy JO, Medeiros DM, Schmidt RE, Saffitz JE, Abel ED, Semenkovich CF, Kelly DP. PGC-1a deficiency causes multi-system energy metabolic derangements: muscle dysfunction, abnormal weight control and hepatic steatosis. PLoS Biol. 2005;3(4):e101. 
53. Lelliott C, Medina-Gomez G, Petrovic N, Kis A, Feldmann HM, Bjursell M, Parker N, Curtis K, Campbell M, Hu P, Zhang D, Litwin SE, Zaha VG, Fountain KT, Boudina S, Jimenez-Linan M, Blount M, Lopez M, Meirhaeghe A, Bohlooly-Y M, Storlien L, Strömstedt M, Snaith M, Oresic M, Abel ED, Cannon B, Vidal-Puig A. Ablation of PGC-1b results in defective mitochondrial activity, thermogenesis, hepatic function, and cardiac performance. PLoS Biol. 2006, 4(11):e369.

54. Holloszy JO. Biochemical adaptations in muscle effects of exercise on mitochondrial oxygen uptake and respiratory enzyme activity in skeletal muscle. J Biol Chem. 1967;242:2278-82.

55. Zerbetto E, Vergani L, Dabbeni-Sala F. Quantification of muscle mitochondria oxidative phosphorylation enzymes via histochemical staining of blue native polyacrylamide gels. Electrophoresis. 1997;18:2059-64.

56. Guderley H. Metabolic responses to low temperature in fish muscle. Biol Rev. 2004;79:409-27.

57. Zhu Z, Yao J, Johns T, Fu K, De Bie I, Macmillan C, Cuthbert AP, Newbold RF, Wang J, Chevrette M, Brown GK, Brown RM, Shoubridge EA. SURF1, encoding a factor involved in the biogenesis of cytochrome c oxidase, is mutated in Leigh syndrome. Nat Genet. 1998;20:337-43.

58. Antonicka H, Mattman A, Carlson CG, Glerum DM, Hoffbuhr KC, Leary SC, Kennaway NG, Shoubridge EA. Mutations in COX15 produce a defect in the mitochondrial heme biosynthetic pathway, causing early-onset fatal hypertrophic cardiomyopathy. Am J Hum Genet. 2003;72:101-14.

59. Williams SL, Valnot I, Rustin P, Taanman JW. Cytochrome c oxidase subassemblies in fibroblast cultures from patients carrying mutations in COX10, SCO1, or SURF1. J Biol Chem. 2004;279:7462-9.

60. Stiburek L, Vesela K, Hansikova H, Pecina P, Tesarova M, Cerna L, Houstek J, Zeman J. Tissue-specific cytochrome c oxidase assembly defects due to mutations in SCO2 and SURF1. Biochem J. 2005;392:625-32.

61. Smith D, Gray J, Mitchell L, Antholine WE, Hosler JP. Assembly of cytochrome-c oxidase in the absence of assembly protein Surf1 p leads to loss of the active site heme. J Biol Chem. 2005;280:17652-6.

62. García-Horsman JA, Barquera B, Rumbley J, Ma J, Gennis RB. The superfamily of heme-copper respiratory oxidases. J Bacteriol. 1994;176(18):5587.

63. Lenka N, Vijayasarathy C, Mullick J, Avadhani NG. Structural organization and transcription regulation of nuclear genes encoding the mammalian cytochrome c oxidase complex. Prog Nucl Res Molec Biol. 1998;61:309-44.

64. Ghezzi D, Zeviani M. Assembly factors of human mitochondrial respiratory chain complexes: physiology and Pathophysiology. In: Kadenbach B, editor. Mitochondrial oxidative Phosphorylation. New York: Springer; 2012. p. 65-106.

65. St-Pierre J, Brand MD, Boutilier RG. The effect of metabolic depression on proton leak rate in mitochondria from hibernating frogs. J Exp Biol. 2000; 203:1469-76.

66. Theron M, Guerrero F, Sebert P. Improvement in the efficiency of oxidative phosphorylation in the freshwater eel acclimated to $10.1 \mathrm{MPa}$ hydrostatic pressure. J Exp Biol. 2000;203:3019-23.

67. Magnoni L, Martos-Sitcha JA, Queiroz A, Calduch-Giner JA, Magalhães Gonçalves JF, Rocha CMR, Abreu HT, Schrama JW, Ozorio ROA, PérezSánchez J. Dietary supplementation of heat-treated Gracilaria and UIva seaweeds enhanced acute hypoxia tolerance in gilthead Seabream (Sparus aurata). Biol Open. 2017;6(6):897-908. doi:10.1242/bio.024299.

68. Salin K, Auer SK, Rey B, Selman C, Metcalfe NB. Variation in the link between oxygen consumption and ATP production, and its relevance for animal performance. Proc R Soc B. 2015;282:20151028.

69. Rogers NJ, Urbina MA, Reardon EE, McKenzie DJ, Wilson RW. A new analysis of hypoxia tolerance in fishes using a database of critical oxygen level (Pcrit). Conserv Physiol. 2016;4(1):cow012.

\section{Submit your next manuscript to BioMed Central and we will help you at every step:}

- We accept pre-submission inquiries

- Our selector tool helps you to find the most relevant journal

- We provide round the clock customer support

- Convenient online submission

- Thorough peer review

- Inclusion in PubMed and all major indexing services

- Maximum visibility for your research

Submit your manuscript at www.biomedcentral.com/submit
Biomed Central 